\title{
KAJIAN PROPORSI WAJAH WAYANG POTEHI PEREMPUAN DI GUDO, JOMBANG DENGAN PROPORSI RASIO EMAS
}

\author{
Hasprita Restiamangastuti Boru Mangunsong a,1,*, Djuli Djatiprambudi b,2 \\ ${ }^{\text {a }}$ Program Pascasarjana Universitas Negeri Surabaya \\ ${ }^{\mathrm{b}}$ Fakultas Bahasa dan Seni Universitas Negeri Surabaya \\ ${ }^{1}$ resti.mangunsong@gmail.com, ${ }^{2}$ djulip@yahoo.com
}

Received 8 Dec 2020; accepted 28 June 2021; published 30 July 2021

\begin{abstract}
The interaction of Nusantara with various nations that has occurred since long ago led to the acculturation of local and immigrant cultures and produced a new culture. One of them is Wayang Potehi which comes from China and develops in Java. The purpose of this study is to find and describe the facial proportions of the female character of Wayang Potehi in Gudo, Jombang. The method used is a quantitative research method by measuring the facial proportions of several female characters of Wayang Potehi in Gudo with the golden ratio theory and calculating the average. In addition, this research also applies interviews with the chairman, Toni, and the puppeteer of Hok Ho An (Wayang Potehi Gudo group), Sonny, as well as direct observation. The golden ratio theory is not used to assess the proportion of Wayang Potehi but as a tool to find the average size of the proportion. The result of this study is the acculturation of Chinese and Javanese culture in visuals, language, stories, characters and characteristics as well as the artists behind the Potehi Wayang. The majority of Wayang Potehi are recognized by the symbols on their clothes and accessories, especially for female characters. Some of the female characters of Wayang Potehi created by the sculptor and Toni's team are quite different from the female characters of Wayang Potehi from China. This shows that the background of the artist (Javanese) influences the work of Wayang Potehi production.
\end{abstract}

\section{KEYWORDS}

Wayang Potehi, Face Proportion, Puppet, Golden Ratio, Indonesian Culture

\section{Pengantar}

Wayang Potehi merupakan salah satu kesenian wayang yang berkembang di nusantara. Wayang Potehi dibawa oleh imigran Tiongkok sekitar abad 16-19. Wayang yang terlihat seperti boneka tangan ini berasal dari Kota Quanzhou, Provinsi Fujian (Hokkian). Di Tiongkok, Wayang Potehi bermula pada Dinsati Han (206 SM - 220 M) dan berkembang pada masa Dinasti Tang (618 - 907 M) dan Dinasti Song (960 - 1279 M) (Yuanzhi, 2005).

Pada mulanya bahasa yang digunakan dalam pertunjukan adalah Bahasa Hokkian. Namun seiring dengan perkembangannya, bahasa yang digunakan bukan hanya Hokkian, tapi juga Bahasa Melayu rendah supaya dapat dimengerti oleh penduduk lokal dan peranakan tionghoa yang sudah tidak mengerti dengan Bahasa Hokkian. Sehingga dapat dikatakan bahwa Wayang Potehi di nusantara berakulturasi dengan budaya lokal, dalam hal ini adalah budaya Jawa dan menjadi berbeda dengan Wayang Potehi yang asli dari Tiongkok. Wayang Potehi ini dikenalkan dan berkembang di beberapa daerah di Pulau Jawa, salah satunya di Kecamatan Gudo, Kabupaten Jombang. Tok Su Kwie, merupakan salah satu dalang / sehu asli Tiongkok yang ada di Gudo, Jombang. Tok Su Kwie mendirikan kelompok seniman Wayang Potehi di Gudo bernama Hok Ho An (Bahasa Hokkian) atau $\mathrm{Fu} \mathrm{He}$ An (Bahasa Mandarin / Bahasa nasional Cina) yang artinya rejeki dan keselamatan.

Salah satu anak dari Tok Su Kwie yang bernamaTok Hong Kie juga menjadi seorang sehu. Semasa hidupnya menjadi seorang sehu, Tok Hong Kie beserta istri dan ketiga anaknya hidup sengsara, bahkan pernah tinggal di kamar bekas kandang ayam. Hal ini membuatnya melarang anak- 
anaknya untuk menjadi sehu karena kehidupan menjadi sehu sangat sulit, mendapatkan uang hanya ketika ada penanggap. Namun Tok Hong Kie setia menjadi seorang sehu karena baginya menjadi sehu adalah untuk menyenangkan hati para dewa. (Kuardhani, 2011).

Namun anak kedua dari Tok Hong Kie, yaitu Tok Hok Lay atau juga biasa disebut Toni Harsono sangat menyukai Wayang Potehi. Toni mematuhi kata-kata ayahnya untuk tidak menjadi seorang sehu, namun dia mempunyai cara tersendiri atas kecintaannya pada Wayang Potehi. Sementara sehu saat ini mayoritas adalah orang Jawa Muslim.

Kecintaan Toni pada Wayang Potehi memang sempat redup ketika memasuki sekolah menengah dan perguruan tinggi. Namun rasa cinta itu tumbuh segar kembali di tahun 2001, ketika Toni sudah memiliki cukup uang hasil kerjanya sebagai seorang wiraswasta, pedagang emas. Ia mengumpulkan wayang-wayang Potehi milik kakekknya dan berburu ke berbagai kota bahkan ke Tiongkok untuk membeli dan meminjam Wayang Potehi. Kemudian ia juga membuat tiruan Wayang Potehi berdasarkan wayang-wayang Potehi yang dia pinjam dan kumpulkan untuk keperluan pementasan.

Wayang Potehi yang direproduksi oleh Toni dikerjakan oleh berbagai seniman lokal. Dalam pembuatannya Toni yang memberi pengarahan dan melakukan koreksi, terkadang ia sendiri juga yang melakukan pengecatan dan menempel rambut. Dalam membuat Wayang Potehi, Toni berusaha untuk tetap mirip dengan Wayang Potehi asli Tiongkok dari kakeknya. Namun peran orang-orang Jawa yang mengerjakan Wayang Potehi tetap terlihat. Bentuk dan proporsi wajah Wayang Potehi yang diproduksi oleh Toni memiliki pergeseran bentuk wajah dari Wayang Potehi yang asli dari Tiongkok. Menurut (Sumardjo, 2000), proses artistik seseorang dikendalikan oleh pengalaman estetiknya. Penciptaan karya seni memang merupakan kerja pengungkapan diri, ekspresi diri, dalam suatu wujud benda seni. Latar belakang para pembuat Wayang Potehi dalam tim Toni tentu berbeda dengan pembuat wayang Potehi asli Tiongkok dan tercermin dalam karyanya.

Wajah adalah pengenal utama manusia. Banyak hal yang dapat membedakan wajah, mulai dari bentuk, warna kulit, ukuran, proporsi dan lainnya (Kurniawan et al., 2015). Dalam pementasan Wayang Potehi terdapat beberapa karakter khusus yang tidak bisa dipentaskan sebagai tokoh lain, namun sebagian besar satu Wayang Potehi dapat dimainkan menjadi beberapa karakter dengan mengganti pakaiannya. Sehingga bentuk wajah hanya menggambarkan sifat atau karakter umum misalnya sifat baik dan jahat, misalnya jika berdahi merah menandakan seseorang yang jahat. Selain itu juga bisa menunjukan posisi seseorang, misalnya mata tokoh laki-laki yang menukik ke atas menandakan ia adalah seorang prajurit. Berdasarkan wawancara yang dilakukan penulis kepada Toni, detail wajah Wayang Potehi juga dipengaruhi oleh siapa pemahatnya walaupun Toni sendirilah yang memimpin produksi dan melakukan koreksi. Toni mengaku memiliki beberapa pemahat untuk membuat Wayang Potehi. Toni mengakui bahwa dalam proses pembuatan Toni hanya menggunakan perkiraan untuk melakukan koreksi apakah wajah dan badan Wayang Potehi yang dibuat timnya sudah menyerupai Wayang Potehi yang asli Tiongkok.

Kajian budaya, seni dan matematika merupakan disipin ilmu yang terkait dengan estetika. Menurut (Junaedi, 2017), penggunaan matematika sebagai upaya perumusan nilai estetis yang disebut dengan golden ratio (perbandingan keemasan), telah dikenal bangsa Yunani Kuno. Golden proportion / golden ratio adalah pengukuran untuk estetka wajah yang paling sering digunakan dalam literatur. Teori ini dicetuskan oleh Leonardo Fibonacci pada abad 12 yang juga dikenal sebagai phi $(\Phi)$, yang besarannya 1.618. Banyak bidang yang menggunakan teori ini termasuk seni, desain, medis terutama ortodontis untuk studi estetika wajah dan bidang-bidang lainnya. Wajah manusia terdiri dari beberapa bentuk mata, bibir dan hidung. Ketiga komponen itu ditata sedemikian rupa dan medefinisikan proporsinya. Kata proporsi menurut (Salam et al., 2020), adalah "perbandingan ukuran".

Berdasarkan uraian di atas, penulis berfokus untuk mendeskripsikan proporsi wajah menggunakan teori rasio emas Wayang Potehi tokoh perempuan yang diproduksi oleh Toni Harsono dan timnya yang berlatar belakang Jawa. Meskipun begitu teori rasio emas mungkin tidak sesuai untuk menilai karya seni Tionghoa-Jawa ini, sehingga teori rasio emas tidak digunakan untuk menilai 
proporsi atau tidaknya wayang, namun sebagai alat untuk menemukan rata-rata pengukuran proporsi wajah Wayang Potehi perempuan. Penulis juga akan memaparkan proporsi wajah Wayang Potehi dari Cina yang dimiliki Toni untuk mempertegas keunikan proporsi wajah Wayang Potehi yang dibuat oleh Toni dan timnya.

\section{Pembahasan}

\subsection{Wayang Potehi sebagai Akulturasi Budaya Tionghoa dan Jawa di Indonesia}

Akulturasi adalah proses multidimensi yang terdiri dari pertemuan antara praktik, nilai dan identifikasi budaya warisan dan budaya penerima (Schwartz et al., 2010). Akulturasi menjelaskan keberadaan berbagai budaya yang bertemu dan membentuk budaya baru.

Wayang telah diakui oleh UNESCO sebagai salah satu warisan dunia, (Subiyantoro et al., 2020). Berdasarkan (Holt, 2000), kata " wayang" memiliki banyak definisi. Dalam arti sempit "wayang" berarti "bayangan", yang menampilkan sejenis boneka kulit pipih dengan pegangan dan tongkat. Dalam pengertian yang lebih luas, "wayang" berarti pertunjukan yang dramatis, drama, tontonan, baik yang tokohnya wayang atau manusia.

Salah satu fungsi Wayang Potehi di nusantara adalah menjadi jembatan antara pendatang Tionghoa dan masyarakat lokal (Jawa). Bentuk asli dari pertunjukan Wayang Potehi menggunakan Bahasa Hokkian. Namun seiring perkembangan zaman, pertunjukan Wayang Potehi tidak hanya menggunakan Bahasa Hokkian, tetapi juga Bahasa Melayu rendah dan Jawa, sehingga pertunjukan tersebut dapat dipahami oleh masyarakat lokal (Jawa) dan generasi muda Tionghoa, yang tidak lagi memahami bahasa Hokkian.

Akulturasi budaya Tionghoa dan Jawa juga terjadi pada pelaku dibaliknya, salah satunya dalang. Saat ini, peran para dalang (sehu), asisten dalang (ji chhiu) dan para musisi (au-tai) bukan lagi Tionghoa, tapi Jawa-Muslim. Perubahan peran tersebut disebabkan tidak adanya penerus dari etnis Tionghoa itu sendiri, dan mereka lebih memilih menjadi donatur dan pemberi dana serta pesanan pertunjukan. Itu terjadi juga karena faktor sejarah. Ketika era Orde Baru, pemerintah melarang semua aktivitas bernuansa Tionghoa atau Cina. Larangan itu menyebabkan generasi muda Tionghoa tidak lagi melirik bidang budaya dan beralih ke bidang ekonomi dan entrepreneurship.

Dewasa ini perkembangan akulturasi Wayang Potehi semakin luas, seperti dalam penggunaan bahasa dan cerita. Toni, ketua kelompok Potehi di Gudo mengatakan, pihaknya masih berupaya agar Wayang Potehi tetap sesuai dengan bentuk aslinya.

\subsection{Wayang Potehi di Gudo, Jombang}

Jombang merupakan salah satu kabupaten di Jawa Timur yang dikenal sebagai Kota Santri karena memiliki banyak pesantren. Berdasarkan data statistik pada website resmi Kabupaten Jombang, kawasan Jombang merupakan kawasan yang strategis karena berada di persimpangan jalan arteri Surabaya - Jombang - Solo dan jalan kolektor primer Malang - Jombang - Babat. Jombang memiliki 21 kecamatan, salah satunya adalah Gudo. Penduduk Gudo beragama Islam, Kristen, Konghucu dan Budha. Berdasarkan data tahun 2017, ada 3.345 orang di Gudo, beragama Islam, 459 orang Kristen Protestan, 224 orang Konghucu, 152 orang Katolik, dan 15 orang Budha. Dulunya, Gudo berpenduduk Jawa dan Tionghoa. Di sekitar areal Gudo berdiri beberapa perkebunan tebu dan pabrik gula kemudian muncul pecinan, orang Tionghoa menjadi mekanik pabrik gula.

Perkembangan Wayang Potehi di Jombang cukup stabil, terutama di Gudo di Kelentheng Hong San Kiong (鳳山宮). Di Gudo terdapat kelompok pelestarian Wayang Potehi yang disebut Fu He An (dalam bahasa nasional Cina) atau Hok Ho An (Bahasa Hokkian). Berdasarkan wawancara penulis dengan salah satu dalang (sehu) yang bernama Sonny, kalimat "Hok Ho An" berarti keberuntungan dan keselamatan. "Hok" berarti beruntung (hoki) "Ho" berarti rejeki, "An" berarti keamanan. Selama 32 tahun masa Orde Baru pagelaran Wayang Potehi di Kelentheng Hong San Kiong masih bisa dilakukan, seperti pertunjukan Barongsay. Hal itu bisa terjadi karena dukungan 
masyarakat dan aparat setempat yang tetap mempersilahkan Kelentheng Hong San Kiong melakukan ritual ibadahnya dan kebudayaannya walaupun dilarang pemerintah.

Berdasarkan wawancara penulis dengan Toni atau Tok Hok Lay (nama Tionghoa), Hong San Kiong didirikan oleh kakeknya, Tok Su Kwie, yang berimigrasi ke Jawa dari Tiongkok sekitar tahun 1920. Tok Su Kwie adalah seorang sehu Wayang Potehi yang kemudian langkahnya diikuti oleh salah satu putranya, Tok Hong Kwie. Berdasarkan (Kuardhani, 2011). Tok Su Kwie meninggal sejak Tok Hong Kwie kecil, sehingga Tok Hong Kie mempelajari Wayang Potehi dari teman ayahnya yang juga berasal dari Tiongkok yaitu Pek Liu Kie. Tok Hong Kwie masih menjadi sehu meskipun hidupnya sulit. Motivasinya adalah untuk menyenangkan Thian (dewa). Karena kesulitan hidupnya sebagai sehu, Tok Hong Kwie melarang anaknya menjadi seorang sehu. Namun anak keduanya, Tok Hok Lay / Toni Harsono, sangat menyukai Wayang Potehi sehingga ia memiliki cara lain untuk tetap dekat dengan Wayang Potehi tanpa menjadi seorang sehu.

Pentas Wayang Potehi di Gudo bercerita menggunakan bahasa Hokkian, Bahasa Jawa serta Bahasa Indonesia menyesuaikan dengan kondisi masyarakat. Saat penulis datang ke Klenteng Hong San Kiong atau untuk pertama kalinya pentas Wayang Potehi diadakan setiap hari pada pukul 15.0017.00 dan 20.00-21.00 untuk menghormati dan menyenangkan para Dewa. Terlihat tidak ada penonton yang berlama-lama menonton pertunjukan Wayang Potehi, namun menurut wawancara penulis kepada Toni (Pimpinan HokHo An, juga Pimpinan Kelenteng Hong San Kiong), pementasan yang ditujukan untuk ritual Konghucu tidak memperdulikan kehadiran. penonton. Itu karena pertunjukan itu ditujukan untuk Dewa. Toni mengatakan, Wayang Potehi dalam ritual Konghucu tidak digunakan sebagai sarana ceramah atau dakwah, namun untuk menghibur Dewa dan sarana berdoa kepada Dewa.

Para dalang / sehu di Kelenteng Hong San Kiong hampir seluruhnya beragama Islam-Jawa. Bahkan pementasan yang bertujuan untuk ritual Kong $\mathrm{Hu} \mathrm{Cu}$ juga dibawakan oleh dalang Muslim Jawa. Hal ini disebabkan semakin berkurangnya minat generasi muda Tionghoa untuk menjadi sehu. Terdapat perbedaan bahasa anatara sehu jawa dan sehu Tionghoa, terutama di pengucapan dialek Hokkiannya. Namun karena latihan, sehu Jawa pun bisa melafalkan Bahasa Hokkien dengan cukup baik. Sonny mengatakan beberapa sehu yang ada di Gudo adalah Sonny, Widodo yang dipercaya menjalankan "Go Potehi", Sutarto, Subur dan anaknya Alfian, Yopi. Ada juga yang meninggal yaitu Sesomo (ayah Sonny) dan Purwanto.

Pentas Wayang Potehi dalam Gudo diawali dengan musik dan penampilan tokoh secara bergantian. Setelah itu dilanjutkan dengan su lam pek, atau puisi empat baris dalam Bahasa Hokkian. Pertunjukan yang dilakukan untuk ritual mengikuti cerita asli dari Tiongkok. Pemilihan cerita yang akan dilakukan juga membutuhkan ritual yang dilakukan oleh juru kunci kelentheng yang disebut bio kong. Dalang mengusulkan beberapa pilihan cerita dan pemilihan cerita dilakukan pada saat ritual, cerita yang terpilih diyakini merupakan pilihan Dewa. Pementasan untuk menyelesaikan sebuah cerita membutuhkan waktu sekitar satu bulan. Untuk Wayang Potehi pementasan di luar kelentheng yang berfungsi sebagai hiburan, cerita yang diceritakan sesuai dengan permintaan penanggap dan penonton. Bahkan, Sonny pernah membawakan ceritanya sendiri yang berjudul "Shalawat Air Hujan", Cerita kerukunan umat beragama. Sonny juga pernah mementaskan kisah kelahiran Yesus di GKI Jombang. Cerita Wayang Potehi juga mengalami beberapa penyesuaian jika dipertunjukkan di sekolah dan universitas. Seperti pentas di Taman Kanak-Kanak Al Iman, cerita yang dikisahkan adalah tentang kehidupan sehari-hari yang mudah dipahami oleh anak-anak, serta pertunjukan di UMM (Universitas Muhammadiyah Malang), ceritanya disesuaikan dengan keadaan anak muda / mahasiswa.

Penyesuaian dan perkembangan juga terjadi pada suatu karakter. Toni pun mengambil sosok Cepot dari Sunda Golek Wayang menjadi salah satu bentuk Wayang Potehi. Namun, Toni mengaku belum pernah mengadaptasi tokoh-tokoh lokal legenda Jawa atau tokoh-tokoh Wayang Purwa menjadi bentuk Wayang Potehi. Toni juga punya mimpi untuk dibuat Ludruk Potehi agar bisa lebih 
dinikmati masyarakat. Hal ini menunjukkan adanya pergeseran fungsi dan bentuk sehingga Wayang Potehi dapat bertahan di tengah perbedaan jaman dan budaya.

Berdasarkan wawancara penulis dengan Sonny, pertunjukan Wayang Potehi di Gudo masih menggunakan alat musik klasik Tionghoa, tidak ada kombinasi dengan alat musik lainnya. Musik klasik Tiongkok yang digunakan termasuk musik perkusi seperti Dongko, Tua Lo, Sio Lo, Tua Pua, Sio $\mathrm{Fa}$, sedangkan alat musik melodisnya adalah Jing $\mathrm{Hu}$, Erl Hu, Jew (terompet). Semua alat musik ini dimainkan oleh 3-4 orang. Dalam musik pengiring, pemutar musik mengikuti kode dari sehu. Menurut Sonny, proses menjadi seorang sehu adalah: pertama, menjadi asisten sehu lalu bermain Dongko, lalu bermain Toa Lo, kemudian bermain Terompet dan menjadi musisi dan sehu. Musik pengiring adalah kesepakatan yang didasarkan pada suasana karakter yang muncul. Musik yang digunakan tidak memiliki aturan baku sehingga bisa menggunakan lagu apa saja.

\subsection{Karakteristik Karakter Wayang Potehi}

Identifikasi tokoh dalam Wayang Potehi adalah dengan menggunakan simbol. Simbol adalah benda, peristiwa, ucapan, bunyi atau bentuk tulisan yang diberi makna oleh manusia. Wayang potehi sebagai seni tradisional memiliki banyak nilai simbolis baik dari segi visual, musik dan cerita. Penulis akan lebih fokus pada pembahasan simbol visual untuk menjelaskan ciri-ciri tokoh Potehi.

Berdasarkan wawancara penulis dengan Toni Harsono, tokoh Wayang Potehi tidak permanen dalam satu wayang. Karakter Wayang Potehi dapat berubah sesuai dengan pakaian dan aksesoris yang digunakan. Hanya sedikit tokoh yang tidak bisa digantikan dengan wayang lain, seperti Kuan Kong yang berwajah merah. Wajah merah Kuan Kong memiliki cerita tersendiri yang menyebabkan wajahnya memerah

Karakter lain yang ditentukan oleh bentuk wajah adalah karakter jahat, seperti beberapa arakter laki-laki yang digambarkan dengan mata melotot yang besar dan garis mata yang tebal. Bagian dahi yang berwarna merah juga menggambarkan karakter jahat. Dahi merah dan mata melotot sering dikombinasikan dengan mulut cemberut untuk menekankan karakter buruk. Karakter jahat ini biasanya digunakan untuk anggota kerajaan, seperti raja, penasehat atau menteri, tergantung dari pakaian dan asesorisnya. Pakaian seorang raja bergambar naga berjari lima dan topi persegi berhiaskan manik-manik emas. Sedangkan menteri, bajunya bergambar naga berjari empat dan memiliki sayap di balik topinya. Berdasarkan (Widyani et al., 2017), naga melambangkan kekuatan. Karakter laki-laki dalam Wayang Potehi memang dilambangkan dengan ragam visual yang lebih luas dan kaya simbol dibandingkan dengan tokoh perempuan.

Identifikasi karakter perempuan dalam Wayang Potehi di Gudo sepenuhnya ditentukan oleh pakaian yang mereka kenakan. Karakter permaisuri dilambangkan dengan busananya yang menampilkan Burung Phoenix dan rumbai yang anggun di roknya. Berdasarkan (Widyani et al., 2017), Burung Phoenix melambangkan keindahan dan keanggunan. Orang awam cenderung berbusana polos atau berbusana motif sederhana. Hal ini pula yang menjadi salah satu alasan penulis mengambil karakter perempuan untuk dianalisis karena bentuk wajah relatif tidak mengandung simbol tertentu. Wajah tokoh-tokoh perempuan dalam Wayang Potehi juga bisa menyiratkan rumusan kecantikan yang sedang ngetren di Tiongkok pada masa lalu

\subsection{Proporsi Wajah Wayang Potehi Perempuan di Gudo, Jombang}

Proporsi emas berdasarkan (Shrestha et al., 2018) adalah proporsi unik dari garis AB menjadi dua bagian dengan cara berikut:

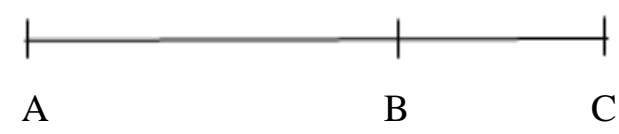

$\mathrm{AB} / \mathrm{AC}=\mathrm{AC} / \mathrm{CB}=1.618$ 
Proporsi emas adalah salah satu ukuran yang paling banyak digunakan untuk estetika wajah di beberapa literatur. Teori proporsi emas dikenalkan oleh ahli matematika, Fibonacci dari abad 12 yang juga mendefinisikannya sebagai phi $(\Phi)$, yang terbilang 1,618. Banyak bidang yang menggunakan teori ini diantaranya seni, desain, kedokteran khususnya ortodontis untuk studi estetika wajah dan bidang lainnya. Wajah manusia terdiri dari beberapa fitur pembentuk termasuk mata, mulut dan hidung. Ketiga komponen itu ditempatkan sedemikian rupa dan menentukan proporsinya. Kata "proporsi" menurut (Salam et al., 2020), adalah "perbandingan ukuran" untuk mendapatkan harmoni. Ketika istilah "proporsi" ini dikenakan pada suatu objek yang tampak wajar naturalistik maka disebut "proporsional" yang artinya perbandingan ukuran yang harmonis. Akan tetapi, kesan harmonis suatu benda bersifat relatif. Pada beberapa objek, harmoni timbul dari perbandingan ukuran yang sesuai berdasarkan standar tertentu yang dibangun melalui hasil penelitian, teori atau kebiasaan alam. Penulis menggunakan teori proporsional rasio emas untuk mendeskripsikan pola proporsi wajah tokoh perempuan Wayang Potehi di Gudo. Teori golden ratio yang berasal dari barat tidak digunakan untuk menilai proporsionalitas kesenian timur seperti Wayang Potehi. Pengukuran dilakukan dengan menggunakan foto empat tokoh perempuan wayang golek Gudo dan dianalisis menggunakan software Corel Draw 2010.

Berdasarkan analisis yang telah dilakukan penulis, rerata tinggi wajah ketiga Wayang Wanita Potehi lokal disajikan pada tabel di bawah ini.

Tabel 1. Rata-rata Tinggi Wajah Potehi Lokal

\begin{tabular}{|c|c|}
\hline $\begin{array}{c}\text { Bagian } \\
\text { Perbandingan }\end{array}$ & $\begin{array}{c}\text { Rerata } \\
\text { Perbandingan }\end{array}$ \\
\hline TR-ME:LC-ME & 1.52 \\
\hline LC-ME:TR-LC & 1.73 \\
\hline TR-LN:LN-ME & 1.51 \\
\hline LN-ME:LC-LN & 2.17 \\
\hline LC-CH:CH-ME & 1.95 \\
\hline CH-ME:LN-CH & 1.25 \\
\hline LC-LN:LN-CH & 1.40 \\
\hline
\end{tabular}

Tabel 2. Rata-rata Total Tinggi Wajah Potehi Lokal

\begin{tabular}{|l|c|}
\hline $\begin{array}{c}\text { Bagian } \\
\text { Perbandingan }\end{array}$ & Rerata Perbandingan \\
\hline TR-ME:TR-LC & 2.63 \\
\hline TR-ME:LN-ME & 2.46 \\
\hline TR-ME:LC-CH & 2.57 \\
\hline TR-ME:TR-TS & 4.34 \\
\hline TR-ME:TS(r-1) & 1.57 \\
\hline TR-ME:LC(r-1) & 2.91 \\
\hline
\end{tabular}

Rata-rata lebar wajah ketiga Wayang Potehi perempuan setempat dapat dilihat pada tabel di bawah ini

Tabel 3. Rata-rata Lebar Wajah Potehi Lokal

\begin{tabular}{|l|c|}
\hline \multicolumn{1}{|c|}{$\begin{array}{c}\text { Bagian } \\
\text { Perbandingan }\end{array}$} & Rerata Perbandingan \\
\hline LC (rl): LN (rl) & 2.89 \\
\hline LC (rl): CH (rl) & 2.54 \\
\hline TS (rl): LC (rl) & 1.02 \\
\hline $\begin{array}{l}\text { LC (rl): jarak antara } \\
\text { mata }\end{array}$ & 3.18 \\
\hline
\end{tabular}


Berdasarkan rerata proporsi tinggi dan lebar wajah, proporsi wajah akan dijelaskan pada gambar di bawah ini

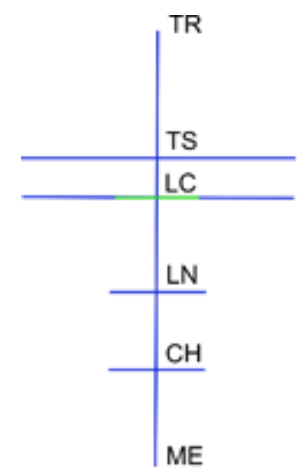

Gambar 1. Parameter Akhir Tinggi dan Lebar Wajah Karakter Perempuan Wayang Potehi Lokal di Gudo (Gambar: Peneliti, 2020)

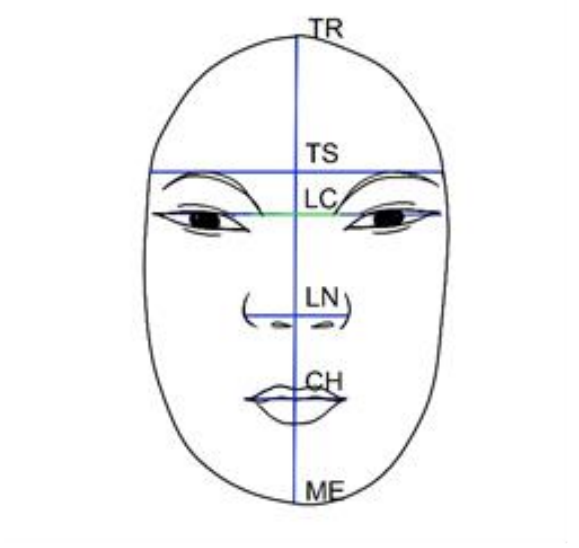

Gambar 2. Sketsa Wajah berdasarkan Parameter Wajah pada Gambar.1

(Gambar: Peneliti, 2020)

Berdasarkan analisis yang dilakukan penulis, terdapat beberapa karakteristik proporsi wajah tokoh Wayang Potehi perempuan yang dibuat oleh seniman lokal. Panjang wajah relatif cukup panjang. Pada detil wajah, jarak antara kedua mata cukup jauh, hidung yang lebar seukuran dengan lebar mulut.

Selain analisa menggunakan teori golden ratio, melalui observasi, penulis juga menemukan ciriciri lain, seperti asimetri bagian wajah antara kanan dan kiri, seperti ketinggian mata dan telinga. Asimetris terhadap wajah wayang lokal bukanlah hal yang disengaja, menurut Toni harusnya simetris. Matanya tidak terlalu besar namun masih terlihat melengkung dan pupilnya besar. Selain itu rambut wayang kulit terbuat dari kayu, bukan dari rambut sintetis atau rambut manusia. Berdasarkan wawancara dengan Toni, rambut wayang yang dibuat timnya bukan dari rambut karena lebih mudah disimpan dan dirawat. Finishing wayang juga terlihat mengkilat. Toni juga menjelaskan bahwa detail Wayang Potehi yang dibuat timnya juga tergantung dari pemahat yang mengerjakan wayang tersebut.

Selain wayang golek buatan tim Toni, ia juga memiliki beberapa wayang buatan Tionghoa, meski tidak sebanyak wayang lokal. Penulis mengambil satu tokoh perempuan dari Wayang Potehi Tiongkok asli untuk dianalisis. Analisis ini tidak dimaksudkan sebagai perbandingan, melainkan untuk menunjukkan adanya pengaruh seniman lokal terhadap perubahan bentuk wajah Wayang Potehi di Gudo, Jombang. 
Berdasarkan analisis yang telah dilakukan penulis, tinggi wajah Wayang Wanita Tionghoa tergambar pada tabel di bawah ini.

Tabel 4. Tinggi Wajah Wayang Potehi Tiongkok

\begin{tabular}{|l|l|}
\hline $\begin{array}{c}\text { Bagian } \\
\text { Perbandingan }\end{array}$ & \multicolumn{1}{c|}{ Perbandingan } \\
\hline TR-ME:LC-ME & 2.23 \\
\hline LC-ME:TR-LC & 0.83 \\
\hline TR-LN:LN-ME & 2.80 \\
\hline LN-ME:LC-LN & 1.36 \\
\hline LC-CH:CH-ME & 2.25 \\
\hline CH-ME:LN-CH & 1.23 \\
\hline LC-LN:LN-CH & 1.69 \\
\hline
\end{tabular}

Tabel 5. Total Tinggi Wajah Wayang Potehi Tiongkok

\begin{tabular}{|l|l|}
\hline $\begin{array}{c}\text { Bagian } \\
\text { Perbandingan }\end{array}$ & \multicolumn{1}{c|}{ Perbandingan } \\
\hline TR-ME:TR-LC & 1.84 \\
\hline TR-ME:LN-ME & 3.87 \\
\hline TR-ME:LC-CH & 3.22 \\
\hline TR-ME:TR-TS & 2.37 \\
\hline TR-ME:TS(r-1) & 1.45 \\
\hline TR-ME:LC(r-1) & 1.97 \\
\hline
\end{tabular}

Lebar wajah Wayang Potehi perempuan asli Tiongkok dijelaskan pada tabel di bawah ini:

Tabel 6. Total Tinggi Wajah Wayang Potehi Tiongkok

\begin{tabular}{|l|l|}
\hline \multicolumn{1}{|c|}{$\begin{array}{c}\text { Bagian } \\
\text { Perbandingan }\end{array}$} & \multicolumn{1}{c|}{ Perbandingan } \\
\hline LC(r-1):LN(r-l) & 3.11 \\
\hline LC(r-1):CH(r-l) & 2.81 \\
\hline TS(r-1):LC(r-l) & 1.36 \\
\hline $\begin{array}{l}\text { LC(r-1) : jarak kedua } \\
\text { mata }\end{array}$ & 2.95 \\
\hline
\end{tabular}

Berdasarkan proporsi tinggi dan lebar wajah, proporsi wajah akan dijelaskan pada gambar di bawah ini

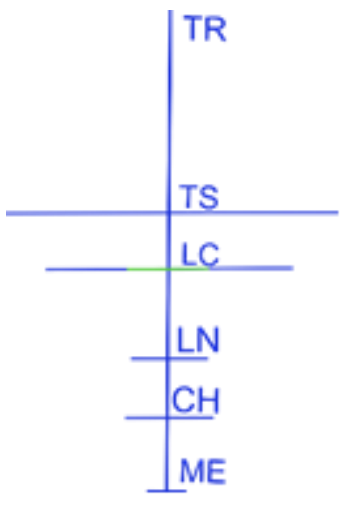

Gambar 3. Parameter Tinggi dan Lebar Wajah Karakter Perempuan Wayang Potehi Tiongkok di Gudo (Gambar: Peneliti, 2020) 


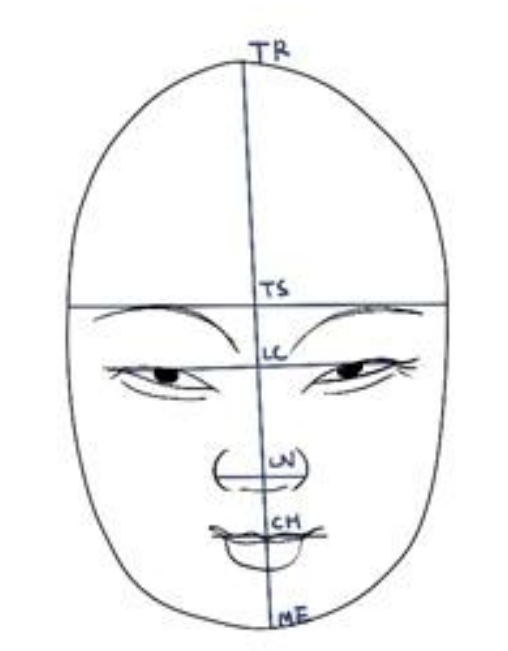

Gambar 4. Sketsa Wajah berdasarkan Parameter pada Gambar.3

(Gambar: Peneliti, 2020)

Berdasarkan analisis yang dilakukan penulis, terdapat beberapa ciri proporsi wajah pada tokoh Wayang Potehi perempuan yang berasal dari Tiongkok. Panjang dahi relatif panjang. Pada detail wajah, jarak antara kedua mata cukup jauh, hidung kecil berukuran sama dengan lebar mulut. Dari perbandingan antara tinggi dan panjang, mukanya relatif lebih bulat daripada buatan lokal.

Selain analisis menggunakan teori golden ratio, melalui observasi, penulis juga menemukan ciriciri lain, seperti bagian muka yang cukup simetris antara kanan dan kiri. Bibir juga dibuat lebih kecil meski warna merah pada bibir tidak memenuhi bibir. Garis mata cukup lurus dan meninggi serta mata dan pupil lebih kecil. Hidung juga dibuat kecil dan tidak terlalu memperlihatkan lubang hidung. Selain itu, rambut wayang juga dibuat bukan dari kayu melainkan dari sesuatu yang menyerupai rambut sintetis atau manusia. Finishing bagian kepala juga berbeda, dengan finishing dough.

Berdasarkan hasil analisis penulis dapat diketahui bahwa terdapat perbedaan yang signifikan pada bentuk wajah, detail wajah dan proporsi. Latar belakang pengukir pada tim Toni (Jawa) mempengaruhi pengalamannya membuat karya. Tentunya para pengukir jawa memiliki pengalaman hidup yang berbeda, realitas dalam kesehariannya dan pengalaman estetika dengan pengukir Cina. Pengalaman pengukir lokal sebagai orang Jawa memengaruhi pengalaman artistik mereka. Pengalaman artistik adalah melakukan pengalaman estetika sebagai dasar untuk menciptakan sebuah karya seni. Fenomena tersebut sesuai dengan (Sumardjo, 2000), bahwa proses artistik dikendalikan oleh pengalaman estetik.

\section{Kesimpulan}

Nusantara yang memiliki posisi strategis geografis ini telah berinteraksi dengan berbagai bangsa asing sejak zaman dahulu seperti India, Eropa, Arab dan Cina. Kehadiran bangsa asing ini mempengaruhi agama, budaya dan seni. Salah satu pengaruh seni dan budaya Tionghoa adalah Wayang Potehi yang masuk ke Nusantara sekitar abad 16-19. Boneka Potehi. Wayang Potehi tumbuh subur di pulau jawa dan telah mengalami akulturasi dengan budaya lokal yaitu budaya jawa. Akulturasi tersebut terjadi dari segi visual, bahasa, cerita, dan seniman di belakangnya.

Akulturasi Tionghoa-Jawa pada Wayang Potehi juga terjadi di Gudo, Jombang. Kelenteng Hong San Kiong adalah sebuah kelenteng di Gudo yang menjadi tempat pelestarian Wayang Potehi. Hok Ho An (Bahasa Hokkian) atau Fu He An (Bahasa nasional Cina) adalah kelompok seniman Wayang Potehi di Gudo yang didirikan oleh Tok Su Kwie, seorang dalang Tionghoa yang datang ke Jawa. Rombongan ini kini dipimpin oleh salah satu cucunya yaitu Toni Harsono / Tok Hok Lay yang juga ketua kelenteng Hong San Kiong. 
Saat ini mayoritas anggota Hok Ho An beragama Islam Jawa. Pembuat, pemusik hingga dalang Wayang Potehi di Gudo mayoritas adalah Jawa-Muslim. Bahkan pementasan Potehi itu untuk ritual Konghucu, dilakukan pemusik dan dalang mayoritas beragama Muslim. Kondisi inilah yang memunculkan akulturasi dalam beberapa cara dalam seni Wayang Potehi di Gudo. Akulturasi yang terjadi adalah bahasa yang bukan lagi sepenuhnya Bahasa Hokkian tetapi sudah bercampur dengan Bahasa Indonesia dan Bahasa Jawa. Cerita-cerita tersebut tidak lagi dipentaskan pada cerita-cerita klasik Tionghoa, tetapi telah disesuaikan dengan penanggap (kecuali untuk kepentingan ritual keagamaan) dan perubahan bentuk visual Wayang Potehi.

Karakter dalam Wayang Potehi banyak ditentukan oleh pakaian dan aksesoris yang dikenakan. Sehingga wayang bisa digunakan dalam beberapa karakter hanya dengan mengganti pakaian dan asesorisnya. Hanya beberapa karakter yang tidak dapat diganti, karakter yang memiliki simbol khusus di wajahnya seperti Kuan Kong. Karakter perempuan dalam Wayang Potehi sangat bergantung pada pakaian mereka. Sehingga wajah-wajah tersebut

Wayang wanita relatif sama karena tidak memiliki simbol khusus di wajahnya. Namun demikian, wajah tokoh perempuan dalam Wayang Potehi Gudo sudah berubah jauh dibandingkan dengan Wayang Potehi yang berasal dari Cina, khususnya pada wayang yang diproduksi oleh tim Toni. Mayoritas pembuat wayang adalah orang Jawa, sehingga terjadi perubahanproporsi dan detail wajah.

Pengkajian proporsi wajah dilakukan oleh penulis dengan menggunakan teori rasio emas, observasi dan wawancara. Penelitian dilakukan terhadap tiga boneka wanita lokal buatan Hok Ho An dan satu boneka wanita buatan Cina. Perubahan proporsi wajah cukup signifikan. Muka tokoh pewayangan perempuan setempat lebih panjang, bermata melengkung dan lebar, pupil besar, hidung lebar yang sama lebar dengan mulut. Selain itu, wajah tidak terlalu simetris, terutama pada ketinggian mata dan telinga. Rambut pada boneka lokal terbuat dari kayu, menjadi satu bagian dengan kepala. wayang lokal juga memiliki finishing mengkilap.

Berbeda dengan wayang lokal, Wayang Potehi buatan Cina memiliki wajah bulat, mata lurus dan sipit serta pupil kecil, hidung mungil yang seukuran dengan lebar mulut. Rambutnya tidak terbuat dari kayu tetapi dari bahan yang kelihatannya rambut, bisa sintetis atau rambut manusia asli, wayang juga memiliki dahi panjang dan finishing dough.

Perbedaan karakteristik proporsi wajah dan detail wajah yang dibuat oleh tim Toni dan yang dibuat di Cina tentunya disebabkan oleh perbedaan pengalaman pembuatnya. Pengalaman tersebut meliputi pengalaman hidup, pengalaman estetika dan pengalaman artistik.

\section{References}

Holt, C. (2000). Melacak jejak Perkembangan Seni di Indonesia. arti.line.

Junaedi, D. (2017). Estetika Jalinan Subjek, Objek dan Nilai. ArtCiv.

Kuardhani, H. (2011). Toni Harsono Maecenas Potehi dari Gudo. Isac Book.

Kurniawan, I. D. G. A., Magdalena, R., \& Susatio, E. (2015). PENGARUH GOLDEN RATIO PADA PROPORSI WAJAH TERHADAP PERSEPSI ESTETIKA WAJAH. E-Proceeding of Engineering, 2, 3047-3053.

Salam, S., Sukarman, Hasnawati, \& Muhaimin, M. (2020). Pengetahuan Dasar Seni Rupa. Media Sembilan Sembilan.

Schwartz, S. J., Unger, J. B., Zamboanga, B. L., \& Szaapocznik, J. (2010). Rethinking the Concept of Aculturation: Implications for Theory and Research. Am Psychol, 65(4), 237-251. https://www.ncbi.nlm.nih.gov/pmc/articles/PMC3700543/pdf/nihms481011.pdf

Shrestha, D. N., Khanal, D. A., \& Wei, D. X. L. (2018). Assessment of Facial Golden Proportions in Chinese Adults in Hunan Province. Orthodontic Journal of Nepal, 8(1), 28-32.

Subiyantoro, S., Kristiani, \& Wijaya, Y. S. (2020). Javanese Cultural Paradoxism: A Visual Semiotics Study on Wayang Purwa Characters of Satria and Raseksa Figure. Harmonia, 1, 19-28. 
Gelar: Jurnal Seni Budaya

Vol 19, No 1 (2021)

ISSN 1410-9700 (print) | 2655-9153 (online)

https://jurnal.isi-ska.ac.id/index.php/gelar

Sumardjo, J. (2000). Filsafat Seni. Penerbit ITB.

Widyani, T., Tjaturrini, D., \& Sutanto, F. (2017). Wayang Potehi : Makna Ragam Hias Hewan pada Dekorasi Panggung Pertunjukan. Parafrase, 17(02), 57-64.

Yuanzhi, P. K. (2005). Silang Budaya Tiongkok Indonesia. PT Bhuana Ilmu Populer.

\section{Narasumber}

1. Toni Harsono (51), Ketua Grup Wayang Potehi “Hok Ho An”. J1. Raya Wangkal Gudo, Gudo, Jombang.

2. Sonny Fran Asmara (43), dalang Wayang Potehi dari Hok Ho An. Jl. Raya Wangkal Gudo, Gudo, Jombang. 